\title{
Effective Exchange Rates in Central and Eastern European Countries: Cyclicality and Relationship with Macroeconomic Fundamentals ${ }^{1}$
}

\author{
Daniel Stavárek ${ }^{2}$, Cynthia Miglietti ${ }^{2,3}$
}

\begin{abstract}
This paper examines the evolution of effective exchange rates in nine Central and Eastern European countries in terms of development trends, volatility and cyclicality. Consequently, it provides direct empirical evidence on the nature of the relationship between effective exchange rates and selected macroeconomic fundamentals, addressing a key precondition of numerous exchange rate determination models and theories that attempt to explain the role of exchange rates in the economy. The results suggest that flexible exchange rate arrangements are reflected in both nominal and real effective exchange rates having higher volatility and variability. Furthermore, the results provide mixed evidence in terms of intensity, direction and cyclicality, but show a weak correlation between exchange rates and fundamentals. Sufficiently high coefficients are found only for money supply. Consequently, using fundamentals for the determination of exchange rates and using the exchange rate to explain economic development may be of limited use for the countries analyzed.
\end{abstract}

Key words: Effective exchange rates, Volatility, Variability, Cycle, High/low analysis, Peak/trough analysis, Cross-correlation

JEL Classification: E32, E44, F31

\section{Introduction}

Since the collapse of the Bretton Woods system in the 1970s and the introduction of floating exchange rates that followed in many countries, there has been a continued debate as to whether and how exchange rates are related to economic fundamentals. In literature, an enormous number of models have been proposed during the floating rate period which assume that various macroeconomic variables influence exchange rates. Many studies have been published that show an empirical application of these models and that aim to explain exchange rate behavior and/or to predict future exchange rate

\footnotetext{
${ }^{1}$ The research behind this paper was supported by the Czech Science Foundation within the project GAČR 13-03783S "Banking Sector and Monetary Policy: Lessons from New EU Countries after Ten Years of Membership". This support is gratefully acknowledged.

2 Department of Finance and Accounting, School of Business Administration, Silesian University, Univerzitní nám. 1934/3, 73340 Karviná, Czechia, e-mail: stavarek@opf.slu.cz.

${ }^{3}$ Department of Applied Sciences, Firelands College, Bowling Green State University, One University Drive, Huron, OH, 44839, USA, e-mail:cmiglie@bgsu.edu.
} 
development. The most influential and widely used models from this period are based on the principles of purchasing power parity and interest rate parity or belong to the class of monetary models of exchange rate determination (Cheung et al., 2005). We can use these monetary models as an example of a conventional set of fundamentals that are usually applied. The fundamentals shared by all models from this class include differentials in money supply, output in the form of gross domestic product or income, longterm interest rate, inflation rate and trade balance (Dal Bianco et al., 2012).

However, Meese and Rogoff (1983) found that fundamentals-based exchange rate models fail to outperform random-walk models. Additionally, De Grauwe and Grimaldi (2006) and other researchers have provided more recent evidence that the relationship between exchange rates and macroeconomic variables is rarely supported by real data and the respective models often fail empirically. The missing relationship between exchange rates and macroeconomic aggregates is known as the "exchange rate disconnect puzzle" and is one of the six major puzzles in international economics described by Obstfeld and Rogoff (2001). As Jindrová (2007) points out, the exchange rate disconnect puzzle consists of two separate phenomena. The first refers to the exchange rate determination puzzle and draws on Meese and Rogoff (1983). The second part of the puzzle refers to extreme (excessive) exchange rate volatility with respect to other macroeconomic fundamentals. There is also evidence that the business cycle properties of macroeconomic aggregates are only slightly affected by the exchange rate regime applied (Dedola and Leluc, 2001).

The interaction between exchange rates and macroeconomic variables can also be examined from the opposite perspective, i.e. how exchange rates affect the fundamentals and the overall economy. It is important to recall that exchange rates can matter both in terms of their level and volatility.

One of the major channels through which the exchange rate affects economic conditions is through its impact on prices. The effect occurs either directly through import prices or indirectly through the impact of price changes on real incomes, customer spending and trade flows, with feedback effects on overall price level. The second key way that the exchange rate affects the economy is through its impact on international trade flows via the expenditure-switching effect. An appreciation in domestic currency implies a reduction in exports and an increase in imports, resulting in an overall deterioration in the trade balance and thus reducing the net trade contribution to GDP growth. Thirdly, a crucial channel through which exchange rates influence the economy is by their effect on the total volume of foreign direct investment and the allocation of investment spending across a range of countries. When a currency appreciates, it increases that country's wages and production costs relative to those of its foreign counterparts. If all else is equal, the attractiveness of the country experiencing real appreciation therefore decreases, and the country is likely to receive less productive capacity investment.

Many researchers have tested for these effects empirically, in a broad spectrum of countries and time periods. However, the evidence provided by their studies is rather mixed, and the effects of exchange rates on the economy have often been found to be insignificant. For instance, Di Mauro et al. (2008) analyzed the changing role of exchange rates in the global economy of the euro area. They concluded that the pass-through effect of exchange rates on both prices and exports has declined as a result of globalization. Fur- 
thermore, ambiguous findings on exchange rate effects were reported by An and Wang (2012), Hoffmann and Holtemöller (2010) and others.

This paper aims to respond to the inconsistencies between a strong theoretical foundation for the relationship between exchange rates and macroeconomic fundamentals and the weak results obtained in empirical studies so far. Its main objective is to identify the nature of this relationship in selected Central and Eastern European countries (CEECs). In addition to providing direct empirical evidence on the relationship between effective exchange rates and a number of fundamentals, we evaluate the short-term volatility and medium-term variability of the exchange rates in these countries. In our empirical estimation, we consider the business cycle and cyclical properties of the variables, which is necessary in order to properly examine the relationship. We work with data for a group of nine CEECs: Bulgaria (BUL), Czechia (CZE), Estonia (EST), Hungary (HUN), Latvia (LAT), Lithuania (LIT), Poland (POL), Slovenia (SLO) and Slovakia (SVK). All of these countries are members of the European Union (EU); eight of them joined the EU in May 2004, while Bulgaria became an EU member state in January 2007. Romania was excluded from the dataset due to data irregularity.

This research is motivated by several factors. First, very few such studies have been published on the new EU member states. Second, our goal is to expand current knowledge on the topic by using effective rather than bilateral exchange rates, so as to better reflect the real economic environment in which countries interact with each other. Third, according to economic theory the development of exchange rates is particularly important to open economies, such as those of the CEECs. Fourth, with the current very low (almost zero) interest rates, exchange rates have been used as a standard monetary policy tool by many central banks. Therefore, the relevance of this subject for policymaking has greatly increased. To mark out the scope of the paper even more precisely it is critically important to note what is not studied and thus not reported in the paper: we neither evaluate the relevance of macroeconomic aggregates in exchange rate determination, nor attempt to predict exchange rate development or estimate the effect of exchange rates on the economy.

The paper has three sections. In the first section, we describe the evolution of effective exchange rates in the CEECs. We apply various techniques to examine short-term volatility, medium-term variability and the phases of the development cycles. Our findings on exchange rate dynamics and phases of cyclical development serve as a starting point for further empirical analysis. In Section 2, we introduce the dataset and empirical methods used for assessing the cyclical relationship between exchange rates and selected macroeconomic aggregates. The results of the cross-correlation between exchange rates and macroeconomic aggregates are reported and discussed in Section 3. In the conclusion, we summarise our main findings and their implications.

\section{Stylized facts on effective exchange rates}

In this section, we examine several aspects of the development of effective exchange rates in the CEECs. An effective exchange rate can be defined as a measure of one economy's currency against a basket of foreign currencies. Each currency in the basket gains a specific weight based on international trade patterns. The effective exchange 
rate can be calculated both in nominal and real terms. The real effective exchange rate (REER) differs from the nominal effective exchange rate (NEER) in that it is adjusted for the domestic price level, relative to price levels in other foreign countries. Since all of the CEECs that we analyze are open economies of relatively small size, they are heavily involved in international trade and capital flow, and have international economic activities with many foreign countries. Hence we use the effective rather than bilateral exchange rates, because they capture the role of exchange rates in the economy more comprehensively and reliably.

The behaviour of effective exchange rates can be analyzed using three time horizons, which differ in their determinants, characteristic features and policy implications. According to Mabin (2010) and as depicted in Figure 1, these three approaches to analyzing the effective exchange rates are as follows:

- The long-term level, which can represent an average or equilibrium exchange rate. This long-term level can be constant over time or can show a long-term trend of continuous domestic currency appreciation or depreciation.

- Medium-term cycles or swings, which reflect deviations from the long-term equilibrium level. The length of the cycle may be several years, and we refer to this as exchange rate variability.

- Short-term volatility, which reflects month-to-month changes in effective exchange rates, up to a maximum of one year. We can observe this as the exchange rate moves around the cyclical exchange rate. These fluctuations in the real effective exchange rate usually stem from changes in the nominal exchange rate.

\section{Figure 1 Stylized path of the evolution of effective exchange rates}

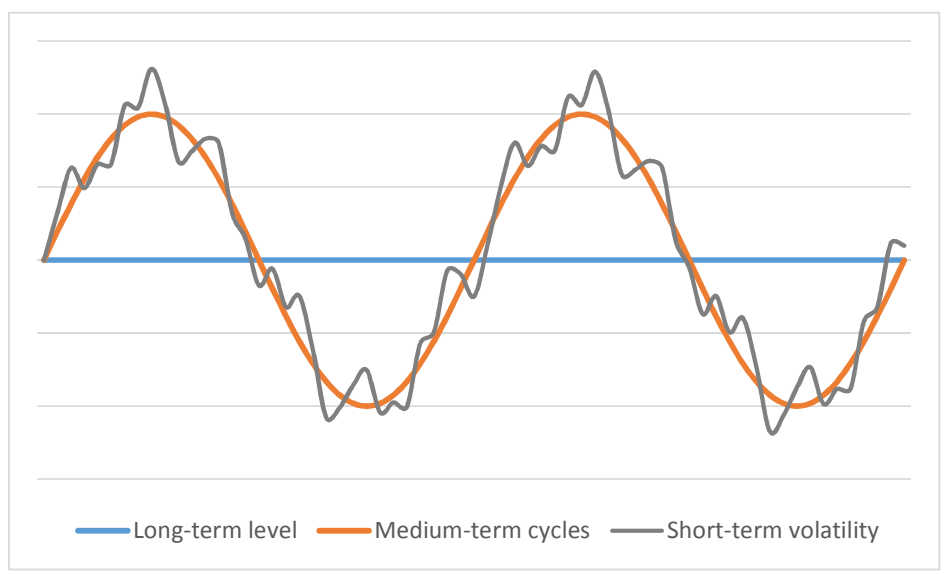

Source: Authors' adaptation based on Mabin (2010, p. 5)

Next, we will introduce the evolution of effective exchange rate indices in the CEECs during the period under examination. In addition, we will explain the development of 
the exchange rate arrangements applied in the CEECs. We will then focus on two aspects of exchange rate development: short-term volatility and medium-term variability in the nominal and real effective exchange rates, as described above.

\section{The evolution of effective exchange rates in the context of exchange rate re- gimes}

Since the entire analysis reported in this paper is based on effective exchanges, we must briefly present and discuss the evolution of NEERs and REERs for the CEECs that we examine. We obtained the time series of both exchange rate indices from the Bank for International Settlements database, and use data covering the period from January 1998 to March 2015 on a monthly basis. The exchange rate indices cover 61 partner economies and are constructed such that an increase in the exchange rate represents an appreciation of the currency.

Figure 2 shows the evolution of these two indices over a period of 14 years. It is evident that the CEECs followed very different development paths, particularly in the case of the NEER. During the first five years of the examined period the gap between the most appreciated (Lithuanian litas) and most depreciated currency (Slovenian tolar) expanded to almost 70 percentage points. Since that time general conditions have not changed significantly and we can distinguish three groups of countries. The first group consists of Lithuania and Czechia, whose currencies achieved the largest nominal effective appreciation, $62.3 \%$ and $50.1 \%$ respectively. By contrast, the second group is composed of Hungary, Slovenia and Poland, whose currencies depreciated over the 14 years and whose exchange rate values at the end of 2013 were weaker than their January 1998 starting values by $18.4 \%, 17.3 \%$ and $3.2 \%$ respectively. The third group includes Slovakia, Bulgaria, Estonia and Latvia, whose currencies maintained a nominal effective appreciation of approximately $20 \%$ over the period examined.

\section{Figure 2 NEER and REER evolution in the CEEC (01/1998-03/2015)}
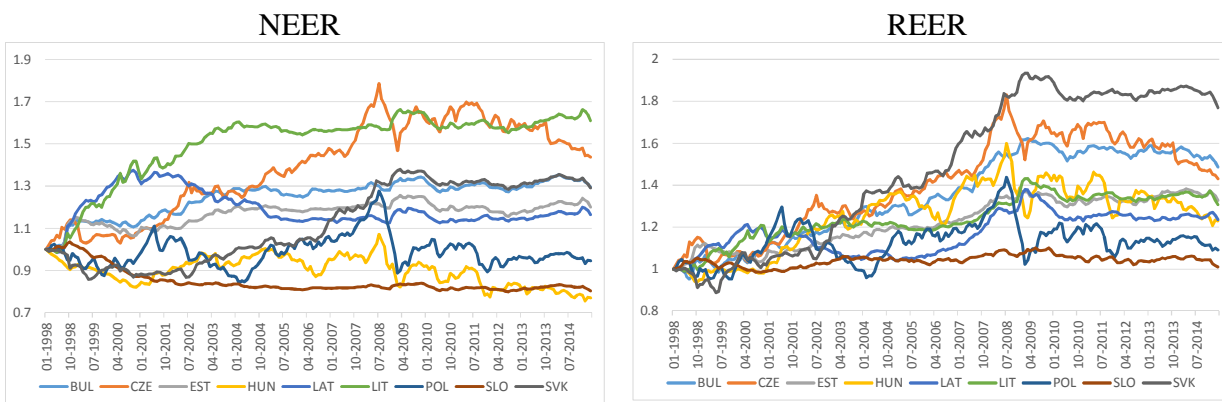

Source: Authors' calculations based on data from the Bank for International Settlements

The evolution of the REER seems to have been more homogeneous across the CEE region over the first five years of the period under examination. All the currencies share a common trend of real appreciation and the rate achieved was approximately $15 \%$. While this trend generally continued, after 2002 the pace of appreciation started to differ 
between the countries. Slovakia and Czechia experienced the fastest real appreciation during the pre-crisis period, followed by Hungary and Bulgaria. In July 2008, the rate of appreciation reached almost $85 \%$ in Slovakia and $80 \%$ in Czechia, as compared to January 1998. The Hungarian and Bulgarian currencies appreciated by $60 \%$ and $55 \%$ respectively during the same years. Real appreciation in effective terms reached about $30 \%$ in all of the Baltic States, but less than $10 \%$ in Slovenia. In the post-crisis period, the exchange rates stabilized at the levels that emerged after the culmination of the volatile crisis period, and so the REER did not change significantly in any of the countries studied.

Table 1 Overview of exchange rate arrangements applied in the CEEC

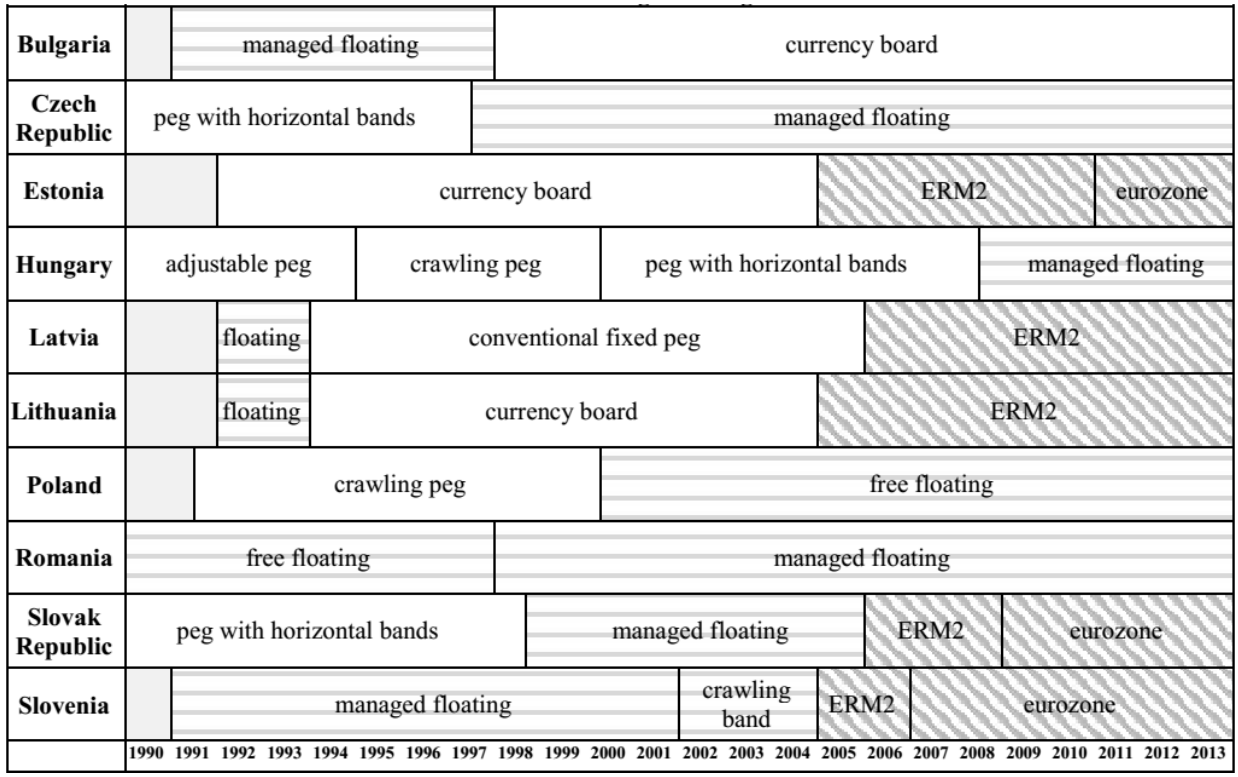

Source: Mirdala (2013, p. 470)

Many aspects of the effective exchange rate development can be fully or partially explained by the exchange rate arrangements applied in each country. The CEECs have used various regimes since the beginning of their economic transformation, as can be seen in Table 1. For example, both the NEER and REER are substantially more volatile in Czechia, Poland and Hungary during the crisis period. These sharp ups and downs within a short period of time distinguish these countries from the rest of the CEE region. Not surprisingly, these were the only three countries that still had their own national currency and followed some form of floating exchange rate regime at that time.

Interestingly, Table 1 shows considerable diversity in exchange rate regimes among the countries. However, several groupings of countries followed similar strategies in their exchange rate policy. The small Baltic countries preferred a fixed arrangement from the very beginning of the transformation process in the early 1990s: Estonia and Lithuania 
adopted a currency board regime, while Latvia followed a conventional fixed peg arrangement. The inclination toward a fixed exchange rate in the Baltic States persisted over the entire period analyzed, and was replaced only by membership in the euro area (Estonia in 2011, Latvia in 2014) and obligatory participation in the Exchange Rate Mechanism II (ERM II).

Even though Czechia, Hungary, Poland and Slovakia embarked on a path of transformation with a fixed or semi-fixed exchange rate regime in the form of peg with horizontal bands or crawling peg, these countries all switched to a managed or free floating arrangement after facing a currency crisis and/or after completing most of the transformation process. Of these, only Slovakia planned to join the euro area and replaced its national currency with the euro in 2009. Due to a low level of reserves and despite high inflation rates, Bulgaria and Slovenia first adopted a managed floating arrangement and then moved to a less flexible exchange rate regime. Bulgaria implemented a currency board due to lack of credibility and Slovenia adopted a crawling band followed by a strategy of expedited membership in the euro area. When interpreting the evolution of NEERs and REERs in the CEECs we must take into consideration these differences in the applied exchange rate regimes, and be conscious of the fact that deviations in the REER in countries with fixed arrangements are mainly driven by changes in relative price levels.

\section{The volatility of effective exchange rates}

This section of the paper is focused on the short-term volatility of NEERs and REERs. Accordingly, we calculate the monthly changes in the exchange rate measures and compute a simple average of these changes over the entire estimation period. In Figure 3 , we present the means and standard deviations of the changes (left graph) and means and standard deviations of absolute changes (right graph). Whereas the mean of monthly changes mainly demonstrates the prevalence of positive or negative exchange rate movements, the mean of absolute changes illustrates their volatility. Additionally, we calculate another standard indicator of volatility, the standard deviation. While the results of this measure are different from those obtained with the means, the standings of the countries and the interpretation of the results remain the same.

The diverse evolution of NEERs, depicted in Figure 2, is reflected in the means of monthly changes seen in Figure 3. The countries that experienced nominal depreciation display negative mean figures or values close to zero. Conversely, the countries with the highest rates of nominal appreciation exhibit the highest positive means of monthly changes. Nevertheless, when assessing the short-term volatility of the effective exchange rates, we should focus primarily on the mean of absolute monthly changes.

Two important findings can be observed in Figure 3. First, the short-term volatility of the REER is higher than the volatility of the NEER in all examined countries. Apparently, changes in relative price levels in the CEECs in relation to other trading partners usually support changes in the NEER and make REER movements more sizeable. This finding is also obvious in countries that are part of the monetary union or that fix their national currency against another currency. In this instance, an economy can only achieve stability against that currency which will fluctuate against other 
currencies. Additionally, the real exchange rate is influenced by relative price movements, which depend on a range of factors that cannot be controlled even in a country with a fixed regime.

Figure 3 Effective exchange rate volatility (01/1998-03/2015)
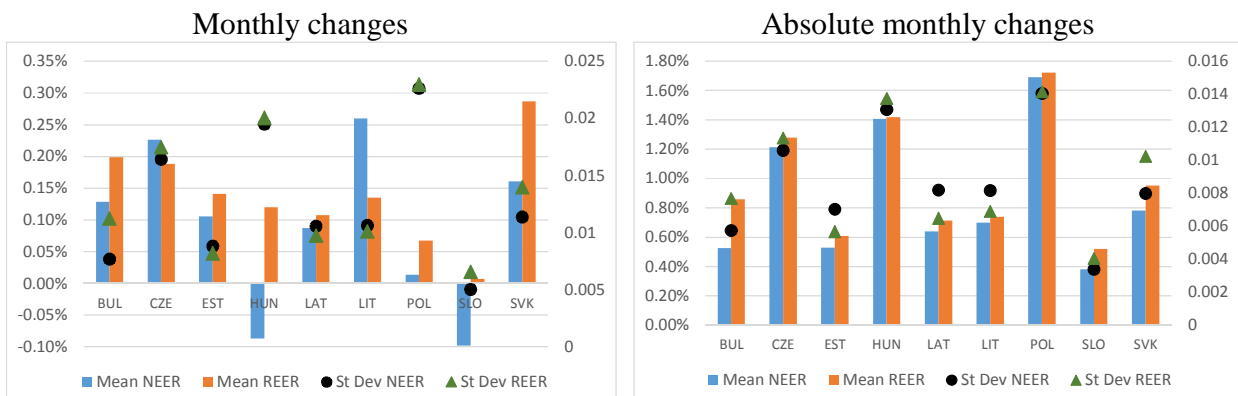

Note: Means of changes are on the left axis, standard deviations of changes are on the right axis Source: Authors' calculations based on data from the Bank for International Settlements

The second finding is that the countries that have been using a floating regime over most of the analyzed period and during the turbulent crisis times show markedly higher exchange rate volatility than the countries with fixed regimes. The most volatile effective exchange rates were revealed for Poland (free floating) and Czechia (managed floating) and Hungary (managed floating in combination with a peg with wide fluctuation bands). The lowest levels of volatility were found in Slovenia and Estonia.

\section{Cycles in effective exchange rate development}

Although an economy may have a volatile currency and exchange rate on a short-term basis, this need not necessarily result in large exchange rate cycles. We apply two measures to assess the medium-term variability of effective exchange rates and to identify cycles in exchange rate development. The first is a high/low analysis over the whole exchange rate time series. It shows the range between the maximum and minimum value of the exchange rate and indicates the span of the exchange range variability. The ranges are delineated in Figure 4 for NEERs as well as REERs. The graphs are supplemented by values of mean and median exchange rate. The latest value in the exchange rate time series is from March 2015.

The results suggest that the variability of exchange rates differs for NEER and REER for all of the countries studied. While the most variable NEERs can be found in Czechia, with a range of about $79 \%$, followed by Lithuania (69\%) and Slovakia (61\%), the most variable REERs were identified in Slovakia (118\%), Czechia (83\%),Bulgaria and Hungary (both 70\%). By contrast, the least variable exchange rates in both measures were identified in Estonia (26\% for NEER and 38\% for REER) and in Slovenia (29\% for NEER and $12 \%$ for REER). 
Figure 4 Effective exchange rate variability - high/low analysis (01/1998-03/2015)
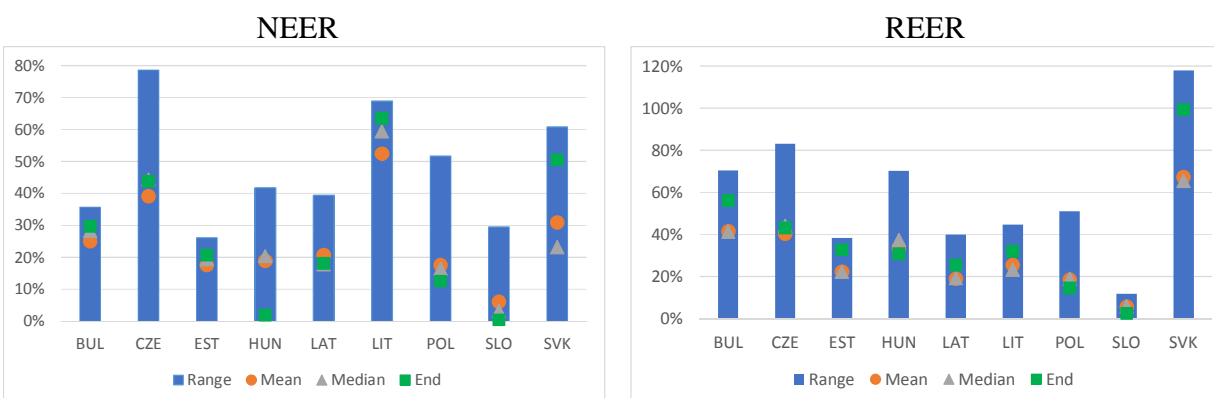

Note: The range is the difference between the highest and lowest exchange rate over the examined period calculated as Range $=(\max -\min ) / \mathrm{min}$. The mean, median and end figures are presented in percentage form relative to the minimum value of the exchange rate series. The end figure refers to March 2015.

Source: Authors' calculations based on data from the Bank for International Settlements

These findings closely correspond to the short-term volatility measured using the mean of absolute monthly changes. For most of the countries, the variability range seems to be balanced, as the mean and median values are situated in the middle of the range. Regarding the exchange rates in March 2015, one can conclude that the most recent exchange rate levels represent neither a peak nor a trough in any of the "floating" countries. The only exception is the NEER in Hungary. On the other hand, the recent figures for the NEERs and REERs in Bulgaria, Lithuania and Slovakia are very close to these countries' historical highs, while both exchange rates in Slovenia depreciated to near historic lows in March 2015. This finding confirms that the exchange rate in countries with an independent national currency and floating exchange rate regime can absorb a portion of a macroeconomic shock such as the financial crisis followed by recession more easily than countries with fixed regimes, or members of the euro area.

Despite being a relatively simple indicator, the high/low analysis provides evidence of the variability of individual exchange rates when compared internationally. However, this approach cannot be effectively applied as a measure of variability and cycles if a series exhibits a structural change in development. Furthermore, the high/low analysis may miss important information about the size of different cycles, and can be influenced by changes in the equilibrium levels of exchange rates. Therefore, Mabin (2010) recommends that high/low analysis be applied in conjunction with a more robust peak/trough analysis.

The peak/trough analysis certainly captures more information about the medium-term variability than the high/low analysis. However, it suffers from one serious drawback: there are no hard and fast rules for the identification of peaks and troughs in the cycle, and these must be determined by the individual researcher. Therefore, numerous techniques and procedures have been used to define the turning points of such cycles.

We use two generally accepted rules for the identification of peaks and troughs. First, the distance between two consecutive peaks (troughs) should be at least 30 months. Second, each phase of the cycle (peak-to-trough or trough-to-peak) should be no less 
than six months long. After applying this approach, we obtain results showing the amplitude of the exchange rate cycles; these results are reported in Figure 5. Our approach for detecting the peaks and troughs differs from the method used in SchmidtHebbel (2006), which would have generated many small phases within a short time period.

Figure 5 Effective exchange rate variability - peak/trough analysis (01/1998-03/2015)
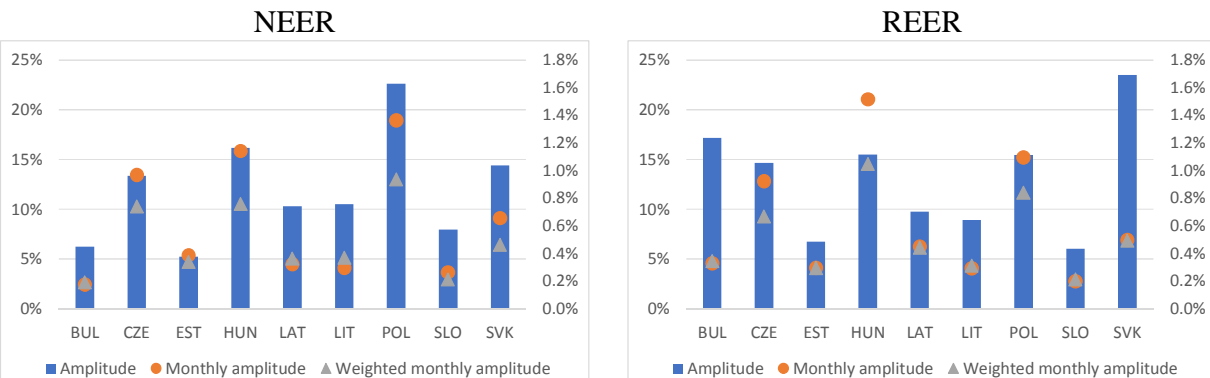

Note: The amplitude is generally calculated as the difference between consecutive peaks (troughs) and troughs (peaks), divided by the midpoint between the peak and trough. The reported figure of amplitude (left axis) is the average of all computed amplitudes for the respective currency over the period of examination. The monthly amplitude (right axis) is the mean of the average monthly amplitudes of all identified peak/trough cycles. The weighted monthly amplitude (right axis) reflects the length of the cycle and assigns a higher weight to longer cycles.

Source: Authors' calculations based on data from the Bank for International Settlements

When we compare the results of the peak/trough and high/low analyses, we find that they are not similar. In addition, the conclusions we can draw from each of these analyses as to which economies operate with the most variable effective exchange rates differ. As far as NEERs are concerned, with the peak/trough analysis the highest variability was found in Poland, Hungary and Slovakia, while the lowest average amplitude was found in Slovenia, Bulgaria and Estonia. If we take REERs into consideration, the most variable exchange rate according to this method was in Slovakia, followed by Bulgaria and Poland, and the least variable exchange rates were in Lithuania, Estonia and Slovenia. The average amplitude figures generally correspond with the average monthly and average weighted monthly amplitude values. A high average amplitude is thus usually closely associated with high monthly amplitudes and vice versa. The only exceptions are for the REERs in Bulgaria and Slovakia. In these time series, our results indicate that there were only a few long and ample phases in the cycle (three phases in Bulgaria and four phases in Slovakia), which naturally makes the average amplitude relatively high and the monthly amplitudes relatively low.

Detailed information on the effective exchange rate cycles is presented in Table 2, where we report the mean duration of the phase, average amplitude and cumulative exchange rate change separately for the peak-to-trough and trough-to-peak phases. We also indicate how many times the respective cycle phase occurred during the complete period of estimation. 
Table 2 Amplitude and duration of effective exchange rate cycles (01/1998-03/2015)

\begin{tabular}{|c|c|c|c|c|c|c|}
\hline & \multicolumn{2}{|c|}{ Bulgaria } & \multicolumn{2}{|c|}{ Czechia } & \multicolumn{2}{|c|}{ Estonia } \\
\hline & NEER & REER & NEER & REER & NEER & REER \\
\hline & \multicolumn{6}{|c|}{ Peak-to-trough } \\
\hline Number of occurrences & 3 & 2 & 5 & 5 & 6 & 4 \\
\hline Mean duration (months) & 25.3 & 32.0 & 12.8 & 14.2 & 10.8 & 14.5 \\
\hline Mean amplitude (\%) & $3.36 \%$ & $6.33 \%$ & $10.00 \%$ & $11.03 \%$ & $3.79 \%$ & $4.11 \%$ \\
\hline \multirow[t]{2}{*}{ Cumulative change (\%) } & $10.07 \%$ & $12.67 \%$ & $49.99 \%$ & $55.16 \%$ & $22.72 \%$ & $16.44 \%$ \\
\hline & \multicolumn{6}{|c|}{ Trough-to-peak } \\
\hline Number of occurrences & 3 & 2 & 5 & 4 & 7 & 4 \\
\hline Mean duration (months) & 35.3 & 68.0 & 23.2 & 31.5 & 19.3 & 31.0 \\
\hline Mean amplitude (\%) & $9.16 \%$ & $28.00 \%$ & $16.71 \%$ & $19.14 \%$ & $6.42 \%$ & $9.35 \%$ \\
\hline \multirow[t]{4}{*}{ Cumulative change (\%) } & $27.47 \%$ & $55.99 \%$ & $83.57 \%$ & $76.56 \%$ & $44.91 \%$ & $37.74 \%$ \\
\hline & \multicolumn{2}{|c|}{ Hungary } & \multicolumn{2}{|c|}{ Latvia } & \multicolumn{2}{|c|}{ Lithuania } \\
\hline & NEER & REER & NEER & REER & NEER & REER \\
\hline & \multicolumn{6}{|c|}{ Peak-to-trough } \\
\hline Number of occurrences & 5 & 5 & 3 & 4 & 3 & 3 \\
\hline Mean duration (months) & 22.2 & 16.2 & 31.0 & 16.0 & 20.7 & 24.3 \\
\hline Mean amplitude (\%) & $17.11 \%$ & $13.76 \%$ & $8.77 \%$ & $7.85 \%$ & $3.66 \%$ & $4.97 \%$ \\
\hline \multirow[t]{2}{*}{ Cumulative change (\%) } & $85.56 \%$ & $68.78 \%$ & $26.31 \%$ & $31.41 \%$ & $10.97 \%$ & $14.91 \%$ \\
\hline & \multicolumn{6}{|c|}{ Trough-to-peak } \\
\hline Number of occurrences & 4 & 5 & 4 & 5 & 4 & 4 \\
\hline Mean duration (months) & 20.3 & 22.0 & 26.5 & 26.8 & 34.3 & 31.5 \\
\hline Mean amplitude (\%) & $14.95 \%$ & $19.24 \%$ & $11.42 \%$ & $11.29 \%$ & $15.62 \%$ & $11.85 \%$ \\
\hline Cumulative change (\%) & $59.82 \%$ & $96.22 \%$ & $45.68 \%$ & $56.47 \%$ & $62.46 \%$ & $47.41 \%$ \\
\hline
\end{tabular}




\begin{tabular}{|c|c|c|c|c|c|c|}
\hline \hline & \multicolumn{2}{|c|}{ Poland } & \multicolumn{2}{c|}{ Slovenia } & \multicolumn{2}{c|}{ Slovakia } \\
\hline & NEER & REER & NEER & REER & NEER & REER \\
\hline & \multicolumn{7}{|c|}{ Peak-to-trough } \\
\hline Number of occurrences & 4 & 6 & 2 & 3 & 3 & 2 \\
\hline Mean duration (months) & 21.3 & 16.5 & 56.5 & 32.0 & 19.7 & 16.5 \\
\hline Mean amplitude (\%) & $23.13 \%$ & $13.81 \%$ & $14.40 \%$ & $5.92 \%$ & $9.41 \%$ & $8.81 \%$ \\
\hline Cumulative change (\%) & $92.51 \%$ & $82.86 \%$ & $28.81 \%$ & $17.75 \%$ & $28.23 \%$ & $17.62 \%$ \\
\hline & \multicolumn{7}{|c|}{ Trough-to-peak } \\
\hline Number of occurrences & 4 & 5 & 3 & 3 & 3 & 2 \\
\hline Mean duration (months) & 27.0 & 20.6 & 25.3 & 30.3 & 42.7 & 78.5 \\
\hline Mean amplitude (\%) & $22.12 \%$ & $17.40 \%$ & $3.70 \%$ & $6.17 \%$ & $19.45 \%$ & $38.23 \%$ \\
\hline Cumulative change (\%) & $88.50 \%$ & $87.02 \%$ & $11.10 \%$ & $18.52 \%$ & $58.35 \%$ & $76.46 \%$ \\
\hline
\end{tabular}

Source: Authors' calculations based on data from the Bank for International Settlements

As a result of our computations, we can draw two general conclusions about the effective exchange rate cycles. First, the peak-to-trough phases are usually shorter than the trough-to-peak phases of the cycle. The exceptions to this rule are both exchange rate indices in Slovenia and the NEER in Latvia. Second, a corresponding conclusion can be drawn from the figures for the mean amplitude of the phase. The average amplitude of the peak-to-trough phase is commonly lower than the trough-to-peak amplitude. This rule holds true in 16 out of 18 cases (the exceptions are for the NEER in Hungary and Slovenia).

In addition to these general conclusions, we can also compare the national characteristics of the exchange rate cycles. The longest average downward phase of the cycle was identified in Slovenia (56.5 months for the NEER and 32 months for the REER). While the longest peak-to-trough phase in NEER also occurred in Slovenia (80 months), the longest decline in REER was revealed in Bulgaria (39 months). Conversely, the shortest average peak-to-trough phase for the NEER was found in Estonia (10.8 months) and for the REER in Czechia (11.2 months). The shortest downward phase of the cycles was 6 months; this was observed in multiple cases across the CEECs.

Regarding the trough-to-peak phase of the cycle, we can summarize that the longest average phase was identified in Bulgaria for the NEER (43.5 months) and in Slovakia for the REER (77 months). The same countries also experienced the longest upward phases. However, the indices are reversed when compared to average figures. The longest trough-to-peak NEER phase occurred in Slovakia (101 months) and the longest phase in the REER was found in Bulgaria (128 months). The shortest average duration of the trough-to-peak phase in the NEER was calculated for Estonia (18 months) and in the REER for Hungary (22 months). The shortest upward phase of the cycle lasted 7 months and occurred several times in various countries. 


\section{Data and methodology for analysis of the cyclical relationship between ex- change rates and macroeconomic fundamentals}

The data gathered consist of the quarterly gross domestic product (GDP), long-term interest rates represented by 10-year government bond yields, the inflow of foreign direct and portfolio investment, the money supply expressed as the M2 monetary aggregate, and the nominal and real effective exchange rates (NEER and REER) over the period from January 1998 to December 2013. Earlier data are available for some of the countries, but we preferred to work with a consistent dataset that excludes observations from turbulent years during the 1990s. The data are in national currencies, market prices, and are seasonally adjusted. The effective exchange rate series used in this part of the paper are composed of 37 main trading partners. The Eurostat database was used for all of the data collected on the economy and finance and the time series of investment inflow were obtained from the databases of national central banks. We focus only on the relationship between exchange rates and macroeconomic fundamentals, but the data also supplies evidence about the relationships between exchange rates and microeconomic (industry-level or company-level) indicators, see e.g. Růčková (2012).

We converted all of the series into logs and used the Hodrick-Prescott filter (HP filter) to obtain a cyclical component for each time series. We then applied cross-correlation to all of the combinations of changes in the cyclical component of the NEER / REER and the macroeconomic variables.

We estimate an unobservable time trend for time series variables using the HP filter, in order to obtain a smoothed-curve representation that is more sensitive to long-term than to short-term fluctuations. Hodrick and Prescott first introduced this procedure in 1980 to estimate business cycles. Interestingly, their paper (Hodrick and Prescott, 1997) was published only 17 years later, after the filter had already been widely used in macroeconomics. An observable macroeconomic time series will be denoted by $y_{t}$. Using the HP filter, then $y_{t}$ decomposes into a nonstationary trend $g_{t}$ and a stationary residual cyclical component $c_{t}$ which gives the following formula:

$$
y_{t}=g_{t}+c_{t}
$$

It should be noted that $g_{t}$ and $c_{t}$ cannot be observed. This means that since $c_{t}$ is a stationary process we can think of $y_{t}$ as a noisy signal for the nonstationary trend $g_{t}$. Thus, the problem condenses down to how to extract an estimate for $g_{t}$ from data on $y_{t}$.

This problem is solved by use of the HP filter, which allocates some weight to a linear trend against the signal $y_{t}$. That weight is represented by $\lambda$. If there is no noise then the signal is fully informative and $\lambda$ is set to zero. As $\lambda$ increases, more weight is given to the linear trend, and for $\lambda \rightarrow \infty, g_{t}$ approaches the ordinary least squares estimate of $y_{t}$ against a linear time trend. From their research, Hodrick and Prescott found that if $c_{t}$ and the second difference of $g_{t}, \Delta \Delta g_{t}$, are identically and independently distributed normal variables with mean zero and variances $\sigma_{c_{t}}^{2}$ and $\sigma_{\Delta \Delta g_{t}}^{2}$, then the best choice of $\lambda$ is $\frac{\sigma_{c t}^{2}}{\sigma_{\Delta \Delta g_{t}}^{2}}$. In general, high frequency data are noisier than low frequency data series, and therefore require a higher value of $\lambda$. For quarterly data, Hodrick and Prescott advised 
that a value of $\lambda=1600$ is reasonable. Assuming an adequately chosen, positive value of $\lambda$, there is a trend component that will minimize:

$$
\min _{\left\{g_{t}\right\}_{t=1}^{T}} \sum_{t=1}^{T}\left(y_{t}-g_{t}\right)^{2}+\lambda \sum_{t=2}^{T-1}\left[\left(g_{t+1}-g_{t}\right)-\left(g_{t}-g_{t-1}\right)\right]^{2}
$$

This equation's first term is the sum of the squared deviations, which imposes a penalty on the variance of the cyclical component. The second term is a multiple $\lambda$ of the sum of the squares of the trend component's second differences. It also penalizes variations in the growth rate (lack of smoothness) of the trend component. This means that the larger the value of $\lambda$, the higher the penalty. Specifically, the HP filter identifies the cyclical component $c_{t}$ from $y_{t}$ by the trade-off of the extent to which the trend component keeps track of the original series $y_{t}$ (good fit) in relation to the prescribed smoothness in the trend component $g_{t}$.

Cross-correlation is a standard method for estimating the degree to which two series are correlated. It assesses how one reference time series correlates with another time series as a function of time shift (lag). This method does not yield a single correlation coefficient but rather an entire series of correlation values. A whole series of correlation coefficients is achieved by shifting one of the series forward and backward in time. Cross-correlation is significant when studying the relationship between time series for two reasons: first, because one series may have a delayed response to the other series, or a delayed response to a common stimulus that affects both series. Secondly, one series' response to another series or to an outside stimulus may be "smeared" in time, such that a stimulus restricted to one observation elicits a response at multiple observations. As is the case with all correlations, cross-correlation will show only statistical associations rather than causation. Therefore, we cannot say whether changes in one time series cause changes in the other, but only whether the two series behave as if this were the case.

When we examine two financial series $x_{t}$ and $y_{t}$, it can be seen that the crosscorrelation at lag (lead) $k$ is defined as follows:

$$
\begin{aligned}
\rho\left(y_{t+k}, x_{t}\right)= & \frac{\operatorname{cov}\left(y_{t+k}, x_{t}\right)}{\sqrt{V\left(y_{t+k}\right)} \sqrt{V\left(x_{t}\right)}} \\
= & \frac{T \sum_{t=k-1}^{T}\left(y_{t+k}-m_{y}\right)\left(x_{t}-m_{x}\right)}{(T+k) \sqrt{\sum_{t=k}^{T}\left(y_{t+k}-m_{y}\right)^{2} \sqrt{\sum_{t=k}^{T}\left(x_{t}-m_{x}\right)^{2}}}}
\end{aligned}
$$

where $\rho$ is the correlation coefficient and $m_{x}$ and $m_{y}$ are the means of the corresponding series. It should be noted that the series can be related in three possible ways: (i) $y_{t}$ can lead $x_{t}\left(\rho\left(y_{t-k}, x_{t}\right) \neq 0\right)$, (ii) $y_{t}$ can lag $x_{t}\left(\rho\left(y_{t+k}, x_{t}\right) \neq 0\right)$, (iii) series can be contemporaneously related $\left(\rho\left(y_{t}, x_{t}\right) \neq 0\right)$. 


\section{Cross-correlation between exchange rates and macroeconomic fundamentals}

We expand the research completed by Duarte et al. (2007) and Stavárek (2013) by running cross-correlations for all eight possible combinations of exchange rates and macroeconomic fundamentals for each country. Consequently, we apply a time shift of up to four lags (leads) on the time series of exchange rate cycles relative to the cycle in the macroeconomic fundamental variable. Thus, we can say that the exchange rate leads the fundamental by $k$ quarters if $\left|\rho\left(y_{t+k}, x_{t}\right)\right|$ is a maximum for a negative $k$, the exchange rate is synchronous with the fundamental if $\left|\rho\left(y_{t+k}, x_{t}\right)\right|$ is a maximum for $k=0$, and the exchange rate lags the fundamental if $\left|\rho\left(y_{t+k}, x_{t}\right)\right|$ is a maximum for a positive $k$. In Figure 6 we present the correlation coefficients that we obtain from this analysis. As can be seen, we report cross-correlations for each country, as well as the average value for the entire group. We complete the analysis of cross-correlations based on the work of Rand and Tarp (2002). We define the exchange rate as procyclical, acyclical, or countercyclical depending on whether the respective correlation coefficient is positive, zero, or negative. Additionally, we deem the exchange rate to be strongly correlated if $0.26 \leq\left|\rho\left(y_{t+k}, x_{t}\right)\right| \leq 1$, weakly correlated if $0.13 \leq\left|\rho\left(y_{t+k}, x_{t}\right)\right| \leq$ 0.26 and uncorrelated if $0 \leq\left|\rho\left(y_{t+k}, x_{t}\right)\right| \leq 0.13$.

Regardless of the macroeconomic fundamental used in the cross-correlations, it is apparent from the graphs that the results differ substantially across the countries both in terms of the value of the correlation coefficients and as regards the shape of the correlation curves. Therefore, the group of nine CEECs examined in this study can by no means be considered to be homogeneous in terms of the relationship between their effective exchange rates and their macroeconomic aggregates.

Before we proceed to discuss the relationships in detail, it is necessary to explain how these correlation curves should be interpreted. We can see that the pattern depicted resembles either the letter $\mathrm{S}$ or the reverse letter $\mathrm{S}$. The $\mathrm{S}$-curve shows that positive correlation coefficients can be found only between the current value of the macroeconomic fundamental and the future value of the exchange rate. In other words, the exchange rate is procyclical if it lags the fundamental but countercyclical if it leads the fundamental. By contrast, the reverse S-curve implies the opposite relationship pointing to the procyclicality of the leading exchange rate and the countercyclicality of the lagging exchange rate. 
Figure 6 Cross-correlation between macroeconomic fundamentals and exchange rates
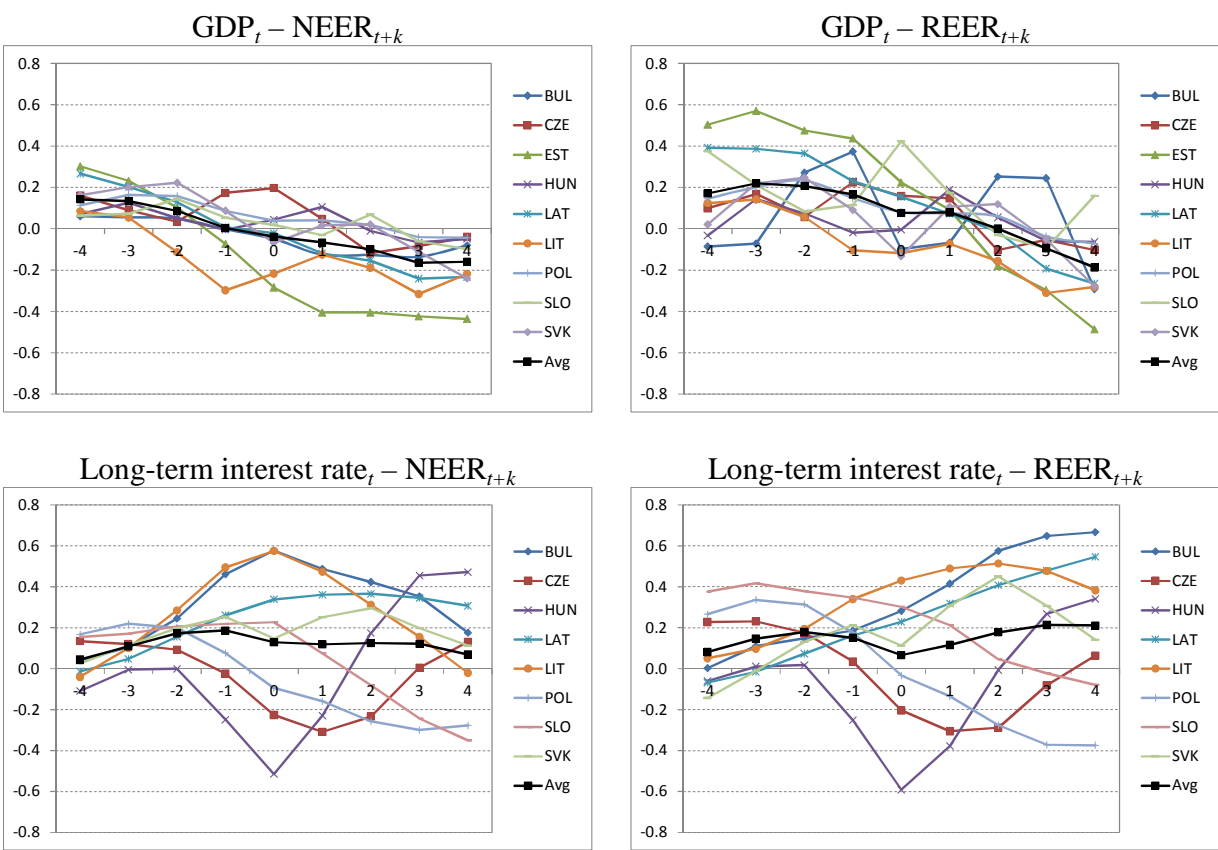

Money supply $_{t}-\mathrm{NEER}_{t+k}$

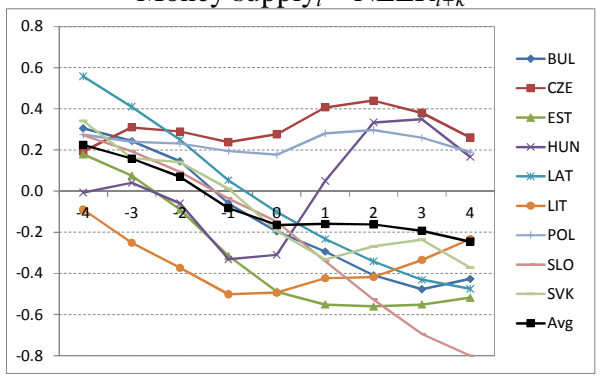

Money supply $_{t}-$ REER $_{t+k}$

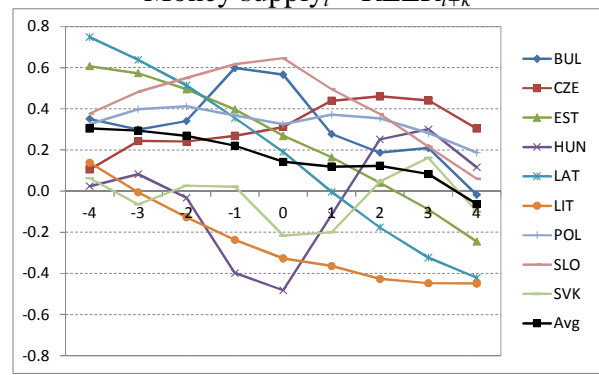



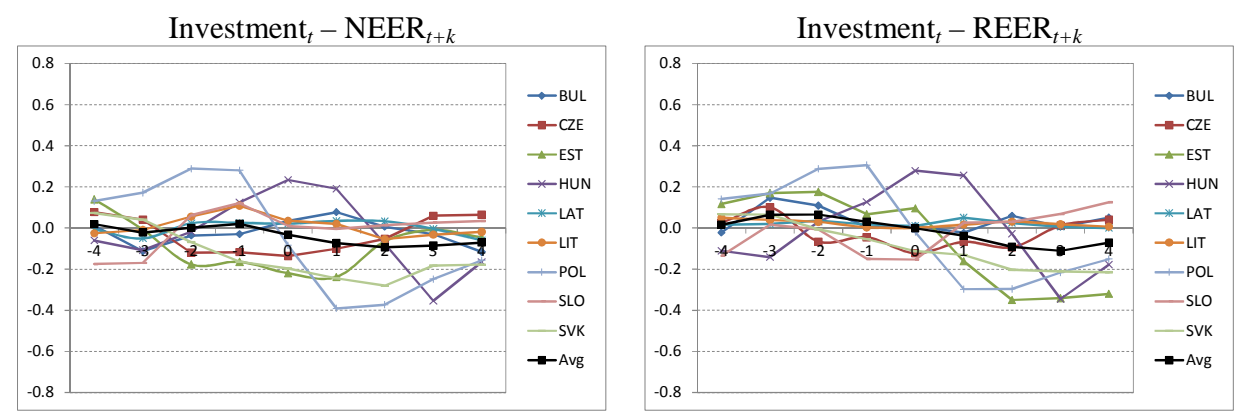

Note: Lags and leads refer to the time shift of the exchange rate series. Estonia is not included in the cross-correlation with long-term interest rates due to data unavailability.

Source: Authors' calculations

The use of two types of effective exchange rate indices in the correlation analysis resulted in considerably different results. While the relationships between the NEER and GDP seem to be more consistent across the countries, the correlations between the REER and GDP vary extensively, while yielding higher correlation coefficients. The average of the absolute values of the correlation coefficients with the REER is higher than the average with the NEER in eight countries. The REER leads the GDP by 1 to 3 quarters. The correlation coefficients are generally positive and range from 0.14 for Hungary to 0.57 for Estonia, indicating that the exhange rate is procyclical as a leading variable. However, Lithuania and Slovenia show the highest coefficient if the REER lags GDP by four quarters. The coefficients are approximately -0.28 and document the countercyclical behaviour of the REER as a lagging variable.

Our correlation analysis between long-term interest rates and exchange rates results in mixed evidence but reveals one common finding. Although eight countries report higher correlation coefficients with the REER than the NEER, these differences are not significant and are generally smaller than 0.10 . While the correlation peaks around lag zero in some countries (Czechia, Hungary, Lithuania), others display an S-curve (Bulgaria, Latvia, Slovakia) and the remaining countries show a reverse S-curve (Poland, Slovenia). The peak of correlation with the NEER around lag zero (e.g. 0.57 for Bulgaria and Lithuania or -0.51 for Hungary) indicates that the NEER is frequently a coincident variable in relation to the long-term interest rate. On the other hand, correlations with the REER typically culminate if the REER lags the interest rate by two or three quarters (e.g. 0.65 for Bulgaria, 0.45 for Slovakia or -0.37 for Poland). Nevertheless, it is impossible to draw any universal conclusion on the form of cyclicality of the REER, because it varies from country to country. The relationship may also be biased due to the use of foreign currencies in lending and the issuance of debt instruments (Kiss and Schuszter, 2014).

The results of our cross-correlations between money supply and exchange rates are also inconsistent and difficult to interpret in a universal way. However, the overall picture seems to be more standardized with the NEER: With the exception of Hungary, Lithuania, and to lesser degree Slovenia, this correlation rises as the time shift of the exchange rate time series increases, in both shift directions. Furthermore, the coefficients obtained in many countries can be considered evidence of a very strong 
correlation (e.g. -0.75 for Latvian REER, -0.80 for Slovenian NEER or 0.61 for Estonian REER). The average correlation coefficients indicate that the NEER is procyclical at lags and countercyclical at leads. In the case of the REER, we observe procyclicality over almost the entire time shift range. Therefore, we can conclude that our results suggest that money supply is the macroeconomic variable most strongly correlated with exchange rates.

The cross-correlation results between investment inflow and exchange rates are the most consistent among all the macroeconomic fundamentals tested in this paper. However, all countries exhibit the lowest correlation coefficients in this combination. The coefficients rarely exceed an absolute value of 0.20 , and the highest correlation coefficient is seen in countries with a floating exchange rate regime, such as Hungary or Poland. The differences in coefficients between correlations with the NEER and with the REER are usually negligible. The resulting average correlation curve is extraordinarily flat when compared to the correlations identified with other macroeconomic fundamentals.

Due to the fact that the graphs in Figure 6 depict only a simple arithmetical average of correlation coefficients, we cannot use this measure to draw any conclusions as to the value of lead/lag where the correlation is the most intensive. Therefore, Table 3 reports the highest average absolute values of the national correlation coefficients and their respective lead/lag at which this mean value peaks. Clearly, coefficients in absolute values cannot be used to examine exchange rate procyclicality and countercyclicality, but only for the assessment of the correlation's strength.

Table 3 Highest average of absolute values of correlation coefficients with respective time shift

\begin{tabular}{|c|c|c|c|c|c|c|c|}
\hline \multicolumn{2}{|c|}{ NEER } \\
\hline \multicolumn{2}{|c|}{ GDP } & $\begin{array}{c}\text { Long-term interest } \\
\text { rate }\end{array}$ & \multicolumn{2}{c|}{ Money supply } & \multicolumn{2}{c|}{ Investment inflow } \\
\hline average & shift & average & shift & average & shift & average & shift \\
\hline 0.1642 & 3 & 0.3001 & 0 & 0.4128 & 3 & 0.1444 & 1 \\
\hline \multicolumn{8}{|c|}{ REER } \\
\hline \multicolumn{2}{|c|}{ GDP } & $\begin{array}{c}\text { Long-term interest } \\
\text { rate }\end{array}$ & Money supply & \multicolumn{2}{c|}{ Investment inflow } \\
\hline average & shift & average & shift & average & shift & average & shift \\
\hline 0.2348 & -3 & 0.2949 & 3 & 0.3704 & 0 & 0.1360 & 3 \\
\hline
\end{tabular}

Source: Authors' calculations

The effective exchange rates appear to have the greatest average correlation with money supply and, to a lesser extent, long-term interest rates. The weakest average correlation was found for investment inflow. The strongest correlation between exchange rates and fundamentals is in most cases demonstrated at leads or lags of three quarters. This conclusion based on the relative strength of correlation for the whole group of CEECs is supported by our findings on the national level. 
Table 4 presents the average of absolute values of the correlation coefficients with all leads and lags. The strength of correlation is distinguished by the background colour: a white background suggests that the respective exchange rate and macroeconomic fundamental are uncorrelated, a grey background highlights a weak correlation and a black background denotes a strong correlation. It should be mentioned that the thresholds delimiting no correlation, weak correlation and strong correlation are 0.13 and 0.26 , respectively. It is apparent from Table 4 that the correlation between money supply and effective exchange rates was found to be strong in seven countries and weak in the two remaining CEECs. There was at least a weak correlation found between longterm interest rates and exchange rates in all countries, while a strong correlation was identified in two countries. Conversely, just a few cases of weak correlation were revealed between investment inflow and exchange rates. No country examined in this analysis shows at least a weak correlation in all combinations of fundamentals and exchange rates. However, we found evidence of some correlation with at least three fundamentals in a majority of countries, and three countries (Bulgaria, Estonia, Lithuania) exhibit a strong correlation with two macroeconomic fundamentals. In contrast, for two countries (Hungary, Slovakia) we found no evidence of strong correlation at all.

Table 4 Averages of absolute values of correlation coefficients in the analyzed countries

\begin{tabular}{|c|c|c|c|c|c|c|c|c|}
\hline & \multicolumn{2}{|c|}{ GDP } & $\begin{array}{c}\text { Long-term interest } \\
\text { rate }\end{array}$ & \multicolumn{2}{c|}{ Money supply } & \multicolumn{2}{c|}{ Investment inflow } \\
\hline & NEER & REER & NEER & REER & NEER & REER & NEER & REER \\
\hline BUL & 0.0760 & 0.1951 & 0.3187 & 0.3371 & 0.2841 & 0.3161 & 0.0504 & 0.0480 \\
\hline CZE & 0.1060 & 0.1241 & 0.1418 & 0.1791 & 0.3104 & 0.3130 & 0.0857 & 0.0636 \\
\hline EST & 0.2958 & 0.3629 & n.a. & n.a. & 0.3702 & 0.3201 & 0.1183 & 0.1999 \\
\hline HUN & 0.0587 & 0.0713 & 0.2452 & 0.2138 & 0.1832 & 0.2002 & 0.1476 & 0.1662 \\
\hline LAT & 0.1529 & 0.2304 & 0.2440 & 0.2555 & 0.3170 & 0.3747 & 0.0286 & 0.0198 \\
\hline LIT & 0.1794 & 0.1521 & 0.2731 & 0.3307 & 0.3466 & 0.2803 & 0.0399 & 0.0218 \\
\hline POL & 0.0782 & 0.1168 & 0.1946 & 0.2536 & 0.2382 & 0.3359 & 0.2363 & 0.2091 \\
\hline SLO & 0.0678 & 0.1848 & 0.1920 & 0.2425 & 0.3452 & 0.4243 & 0.0684 & 0.0791 \\
\hline SVK & 0.1254 & 0.1407 & 0.1775 & 0.2017 & 0.2286 & 0.1000 & 0.1587 & 0.1184 \\
\hline
\end{tabular}

Source: Authors' calculations

\section{Conclusions}

According to theory, exchange rates play an important role in the economy. On the one hand, exchange rates should be affected and determined by a variety of macroeconomic fundamentals. On the other hand, it is assumed that exchange rates influence economic development in many ways on both a microeconomic and macroeconomic level. In this paper, we have neither proposed nor tested the validity of any exchange rate determination models, nor have we estimated the impact of exchange rates and their volatility on the economy. Instead, we have thoroughly examined the volatility and 
cyclicality of the effective exchange rates in nine CEECs. Based on the results we have obtained, we have focused on the elementary preconditions of those theories and models and provided direct empirical evidence for the existence and nature of the relationship between exchange rates and fundamentals.

We have identified substantial differences in the results across the countries, which might have prevented us from drawing general conclusions and straightforward interepretations. However, several of our findings are applicable to most of the countries studied. The countries that applied a floating exchange rate arrangement during the period studied usually experienced higher volatility and cycle phases with higher amplitude. We have established that this remains true regardless of the type of effective exchange rate used. In all of the countries examined, the trough-to-peak phase lasted longer than the peak-to-trough phase. Likewise, the average amplitude of the upward phase was typically higher than the amplitude of the downward phase of the cycle.

There is usually no substantial difference in the strength of the relationship between the exchange rates and the macro fundamentals when we compare results based on the NEER and the REER. Therefore, the results do not confirm the theoretical assumption that in small open economies the REER is more tightly related to macroeconomic fundamentals than the NEER. Instead, our findings indicate that the REER is more related to the international competitiveness of an economy. While money supply seems to be the most highly correlated fundamental, relatively weak relationships were also revealed between exchange rates and foreign investment inflow. However, the results obtained enable us to conclude that policy analyses related to business cycles should not overemphasize the effects of exchange rates on the economy and crucial fundamentals. Furthermore, the standard exchange rate determination models may be of limited applicability in CEECs.

\section{References}

AN, L., WANG, J., 2012: Exchange rate pass-through: Evidence based on vector autoregression with sign restrictions. Open Economies Review, vol. 23, no. 2, pp. 359-380.

CHEUNG, Y.W., CHINN, M.D., PASCUAL, A.G., 2005: Empirical exchange rate models of nineties: Are any fit to survive? Journal of International Money and Finance, vol. 24, no. 7, pp. 1150-1175.

DAL BIANCO, M., CAMACHO, M., QUIROS, G.P., 2012: Short-run forecasting of the euro-dollar exchange rate with economic fundamentals. Journal of International Money and Finance, vol. 31, no. 2, pp. 377-396.

DEDOLA, L., LELUC, S., 2001: Why Is the Business Cycle Behaviour of Fundamentals Alike across Exchange Rate Regimes? International Journal of Finance \& Economics, vol. 6, no. 4, pp. 401-419.

DE GRAUWE, P., GRIMALDI, M., 2006: Exchange Rate Puzzles: A Tale of Switching Attractors. European Economic Review, vol. 50, no. 1, pp. 1-33. 
DI MAURO, F., RUEFFER, R., BUNDA, I., 2008: The changing role of the exchange rate in a globalised economy. Occasional Paper Series 94. Frankfurt am Main: European Central Bank.

DUARTE, M., RESTUCCIA, D., WADDLE, A.L., 2007. Exchange Rates and Business Cycles across Countries. Federal Reserve Bank of Richmond Economic Quarterly, vol. 93, no. 1, pp. 57-76.

HODRICK, R.J., PRESCOTT, E.C., 1997: Postwar US Business Cycles: An Empirical Investigation. Journal of Money, Credit \& Banking, vol. 29, no. 1, pp. 1-16.

HOFFMANN, M., HOLTEMÖLLER, O., 2010: Transmission of nominal Exchange Rate Changes to Export Prices and Trade Flows and Implications for Exchange Rate Policy. The Scandinavian Journal of Economics, vol. 112, no. 1, pp. 127-161.

JINDROVÁ, M., 2007: Exchange Rate Dynamics and the Disconnect. Acta Oeconomica Pragensia, no. 2007/4, pp. 56-68.

KISS, G.D., SCHUSZTER, T., 2014: What are the Differences Between the Currencies of Foreign Exchange Loans? Public Finance Quarterly, vol. 59, no. 2, pp. 187-206.

MABIN, G. 2010. New Zealand's Exchange Rate Cycles: Evidence and Drivers. New Zealand Treasury Working Paper 10/10. Wellington: New Zealand Treasury.

MEESE, R.A., ROGOFF, K.S., 1983: Empirical exchange rate models of the seventies: Do they fit out of sample? Journal of International Economics, vol. 14, no. 1, pp. 3-24.

MIRDALA, R., 2013: Exchange Rate Pass-through to Domestic Prices under Different Exchange Rate Regimes. Journal of Applied Economic Sciences, vol. 8, no. 4(26), pp. 466-491.

OBSTFELD, M., ROGOFF, K.S., 2001: The six major puzzles in international economics: Is there a common cause? In: NBER Macroeconomics Annual 2000, edited by Bernanke, B.S., Rogoff, K.S., pp. 339-412. Cambridge, MA: MIT Press.

RAND, J., TARP, F., 2002: Business Cycles in Developing Countries: Are They Different? World Development, vol. 30, no. 12, pp. 2071-2088.

RU゚ČKOVÁ, P., 2012: Profitability as Basic Criterion of Efficient Management in Context of Crisis Development. In: Proceedings of $13^{\text {th }}$ International Conference on Finance and Banking, edited by Stavárek, D., Vodová, P. Karviná: Silesian University, School of Business Administration, 2012, pp. 313-320.

SCHMIDT-HEBBEL, K., 2006: New Zealand's monetary and exchange-rate policy in international comparison. In: Testing stabilisation policy limits in a small open economy: Proceedings from a macroeconomic policy forum, pp. 83-144. Wellington: Reserve Bank of New Zealand.

STAVÁREK, D., 2013: Cyclical relationship between exchange rates and macrofundamentals in Central and Eastern Europe. Ekonomska Istraživanja - Economic Research, vol. 26, no. 2, pp. 83-98. 